\title{
Drug combinations with quercetin: doxorubicin plus quercetin in human breast cancer cells
}

\author{
Davide Staedler • Elita Idrizi • \\ Blanka Halamoda Kenzaoui • \\ Lucienne Juillerat-Jeanneret
}

Received: 9 December 2010/ Accepted: 19 February 2011/Published online: 13 March 2011

(c) Springer-Verlag 2011

\begin{abstract}
Purpose Doxorubicin is a first-line chemotherapeutic for breast cancer; however, it is associated with severe side effects to non-tumoral tissues. Thus, it is necessary to develop new therapeutic combinations to improve doxorubicin effects at lower concentration of the drug associated with protective effects for non-tumoral cells. In this work, we evaluated whether the plant-derived flavonoid quercetin may represent such an agent.

Methods The effects of doxorubicin and quercetin as single agents and in combination were evaluated on cell survival, DNA and protein synthesis, oxidative stress, migratory potential and cytoskeleton and nucleus structure in highly invasive and poorly invasive human breast cancer cells in comparison with non-tumoral human breast cells.

Results In human breast cancer cells, quercetin potentiated antitumor effects of doxorubicin specifically in the highly invasive breast cancer cells and attenuated unwanted cytotoxicity to non-tumoral cells. Quercetin interfered with cell metabolism, GST activity, cytoskeleton and invasive properties specifically in breast tumor cells compared with non-tumoral breast cells. Doxorubicin induced DNA damage in tumor and non-tumor cells; however,
\end{abstract}

D. Staedler · E. Idrizi · B. H. Kenzaoui · L. Juillerat-Jeanneret Centre Hospitalier Universitaire Vaudois (CHUV) and

University of Lausanne (UNIL), Lausanne, Switzerland

L. Juillerat-Jeanneret $(\bowtie)$

Institute of Pathology, University of Lausanne,

Rue du Bugnon 25, 1011 Lausanne, Switzerland

e-mail: lucienne.juillerat@chuv.ch quercetin reduced this damage only in non-tumoral cells, thus offering a protective effect for these cells. Quercetin also induced polynucleation in aggressive tumor cells, which was maintained in combination with doxorubicin.

Conclusions By combining quercetin with doxorubicin, an increase in doxorubicin effects was obtained specifically in the highly invasive breast cancer cells, while in nontumoral cells quercetin reduced doxorubicin cytotoxic side effects. Thus, quercetin associated with doxorubicin demonstrated very promising properties for developing chemotherapeutics combinations for the therapy of breast cancer.

Keywords Quercetin - Doxorubicin - Breast cancer cells · Tyrosine protein kinases - Polynucleation - Genotoxicity

\section{Introduction}

The response to breast cancer chemotherapy is dependent on the subtype of the tumor, luminal-type breast cancer have a lower risk of metastasis and relatively good clinical outcome, whereas basal-type cancers are highly invasive, progress aggressively and have a poor prognosis. The invasive properties of cancers are dependent on epithelial cell capacity for migration and epithelial-to-mesenchymal transition. In this process, epithelial cells loose their epithelial characteristics and acquire migratory mesenchymal cell-like properties. Thus, for evaluating therapeutic efficacy of single agents as well as combination of chemotherapeutics, it is necessary to evaluate them in human mammary cells representative of these different phenotypes. For chemotherapy, drug combinations are mostly used [1] and presently, anthracyclines such as doxorubicin are used in first-line treatment $[2,3]$. 


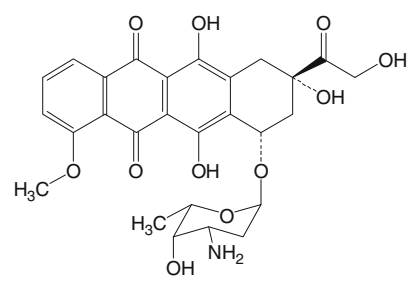

However, doxorubicin has limits in clinical use due to the development of resistance by tumor cells and toxicity for healthy tissues [3, 4]. Thus, to improve therapy regimen with doxorubicin, it is necessary to evaluate new and more tumorspecific doxorubicin-based combination therapies, targeting several cellular pathways and able to reduce the concentration of drug necessary for efficacy, the emergence of drug resistance, and the adverse side effects of chemotherapy [2].

Quercetin $\left(3,3^{\prime}, 4^{\prime}, 5,7\right.$-pentahydroxyflavone) is a plantderived flavonoid present in the diet

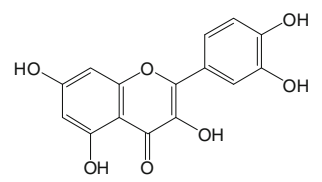

which displays antioxidant, anti-inflammatory, and anticancer properties [5-7], including in human cancers [6, 8-14]. Longterm treatment with quercetin results in pro-apoptotic effects that are correlated with decreased levels of GSH [15], a substrate for the phase II drug-metabolizing enzymes glutathione S-transferases (GST) that covalently link electrophilic compounds with (GSH), in particular GST-P1- $1 / \pi$ overexpressed in cancer, including breast cancer [16-19]. Quercetin has been evaluated in phase I clinical trials for hematological malignancies as a tyrosine kinase inhibitor without myelosuppressive or other serious side effects [6]. Several experimental in vitro and in vivo studies have evaluated quercetin in combination with classical or new anticancer drugs for breast cancer treatment, showing synergistic effects [20-23]. In murine models of breast cancer, quercetin reduced breast cancer cell proliferation when combined with the polyphenols resveratrol and catechin [21], and in combination with doxorubicin, quercetin improved the efficacy and the therapeutic index of doxorubicin, while decreasing doxorubicin-mediated toxicity [22-24]. Our aims were thus to evaluate doxorubicin-based chemotherapeutic combination with the natural compound quercetin for human mammary cells, either cancer cells of increasing aggressiveness or non-tumoral cells.

\section{Materials and methods}

Cells and cell treatments

MDA-MB-231 and MCF-7 cells were obtained from the ATCC (American Tissue Culture Collection, Manassas,
VA, USA). MCF-10A cells were a gift from C. Brisken (EPFL, Lausanne, Switzerland). MDA-MB-231 and MFC7 cells were grown in Dulbecco's modified Eagle medium (DMEM) containing $4.5 \mathrm{~g} / 1$ glucose, $10 \%$ heat-inactivated fetal calf serum (FCS), and penicillin/streptomycin (all cell culture reagents were obtained from Invitrogen, Basel, Switzerland). MCF-10A cells were grown in DMEM medium containing $4.5 \mathrm{~g} / 1$ glucose, $5 \%$ heat-inactivated horse serum, and penicillin/streptomycin, supplemented with $10 \mu \mathrm{g} / \mathrm{ml}$ insulin, $20 \mu \mathrm{g} / \mathrm{ml}$ hydrocortisone, $20 \mathrm{ng} / \mathrm{ml}$ epidermal growth factor (EGF) and $100 \mathrm{ng} / \mathrm{ml}$ cholera toxin (all from Sigma-Aldrich, Buchs, Switzerland). Unless otherwise specified, cells were grown for $24 \mathrm{~h}$ in 48-well plates (Costar, Corning, NY, USA), and then doxorubicin, quercetin or a combination of both, diluted with fresh complete culture medium, was added at the indicated concentrations for 24-72 h.

\section{Chemicals}

Quercetin (purity $\geq 98 \%$ ) was obtained from SigmaAldrich. Quercetin solutions were freshly prepared immediately before use at $100 \mathrm{mM}$ in dimethylsulfoxide (DMSO, Sigma-Aldrich) and then diluted with cell culture medium. DMSO concentration in cell culture medium never exceeded $0.1 \%$, and at this concentration, DMSO had no effects on cell functions (results not shown). Doxorubicin (Actavis, Switzerland) was obtained from the Pharmacy of the CHUV and was dissolved at $10 \mathrm{mM}$ in $0.9 \%$ $\mathrm{NaCl}$ and stored in aliquots at $-20^{\circ} \mathrm{C}$.

\section{Determination of cytotoxicity}

Following exposure to the chemicals, cell viability was evaluated using the MTT (3-(4,5-dimethyl-2-thiazoyl)-2,5diphenyltetrazolium bromide, Sigma-Aldrich, $200 \mu \mathrm{g} / \mathrm{ml}$ final concentration) assay, essentially as previously described [25]. Absorbance at $540 \mathrm{~nm}$ was measured in a multi-well plate reader (iEMS Reader, Labsystems, Bioconcept, Allschwil, Switzerland), and the absorbance values of treated cells were compared with the absorbance values of untreated cells. Experiments were conducted in quadruplicate wells and repeated twice. Means \pm standard deviations (SD) were calculated.

Evaluation of DNA and protein synthesis

Thymidine and leucine incorporation was used to assess DNA and protein synthesis, respectively, essentially as previously described [25]. Briefly, following cell exposure to the chemicals for $72 \mathrm{~h}$, tritiated thymidine $\left({ }^{3} \mathrm{H}-\mathrm{T}\right)$ (Amersham-Pharmacia, Glattbrugg, Switzerland, $400 \mathrm{nCi} /$ $\mathrm{ml}$ final concentration) or tritiated leucine $\left({ }^{3} \mathrm{H}-\mathrm{Leu}\right)$ 
(American Radiolabeled Chemicals, St. Louis, USA; $400 \mathrm{nCi} / \mathrm{ml}$ final concentration) was added to the cells for $4 \mathrm{~h}$. Then, the cell layers were precipitated with trichloroacetic acid, dissolved in sodium dodecyl sulfate in $0.1 \mathrm{~N}$ $\mathrm{NaOH}$ and scintillation cocktail (Optiphase HI-Safe, PerkinElmer, Beaconsfield, UK). Radioactivity was counted in a $\beta$-counter (WinSpectra, Wallac, Germany). The radioactivity counts of treated cells were compared with the radioactivity counts of untreated cells. Experiments were conducted in quadruplicate wells and repeated twice. Means \pm SD were calculated.

\section{Determination of reactive oxygen species}

ROS production by cells was detected by measuring the oxidation of dihydroethidium to ethidium by cells following exposure to the chemicals for $72 \mathrm{~h}$. After the treatments, the cell layers were washed with PBS, and then $250 \mu \mathrm{l} /$ well of $100 \mu \mathrm{M}$ dihydroethidium (Sigma-Aldrich) in DMEM without phenol red (Invitrogen) and without FCS was added to the cell layers for $15 \mathrm{~min}$ at $37^{\circ} \mathrm{C}$ in the dark. Then, the cells were washed with PBS and lysed with $0.1 \%$ Triton X-100 (Sigma-Aldrich) in PBS. For a positive control, the cells were exposed for $1 \mathrm{~h}$ to $3 \mathrm{mM}$ tert-butyl hydroperoxide (Sigma-Aldrich) before the addition of dihydroethidium. Ethidium fluorescence was measured in a fluorescence multi-well plate reader (Cytofluor PerSeptive BioSystems, BioConcept, Basel, Switzerland) at $\lambda_{\mathrm{ex}} / \lambda_{\mathrm{em}}=485 / 580 \mathrm{~nm}$. Fluorescence of treated cells was compared with the fluorescence of untreated cells. Experiments were conducted in triplicate wells and repeated three times. Results were normalized according to the protein content and expressed as percentage of the control cell values. Means \pm SD were calculated. ROS production was also determined using 5-(and-6)-carboxy-2',7'-dichlorodihydrofluorescein diacetate (DCFH-DA). Following treatments, the cell layers were washed with PBS, and $250 \mu \mathrm{l} /$ well of $20 \mu \mathrm{M}$ DCFH-DA (Invitrogen) in Hank's buffer solution (HBSS, Invitrogen) was added for $40 \mathrm{~min}$ at $37^{\circ} \mathrm{C}$. As positive control, cells were exposed for $1 \mathrm{~h}$ to $3 \mathrm{mM}$ tert-butyl hydroperoxide before the addition of DCFH. Fluorescence of DCF was measured in a fluorescence multi-well plate reader (Cytofluor) at $\lambda_{\mathrm{ex}} / \lambda_{\mathrm{em}}=485 / 527 \mathrm{~nm}$. Experiments were conducted in triplicate wells and repeated three times. Results were normalized according to the protein content, and the fluorescence of treated cells was compared with the fluorescence of untreated cells. Means \pm SD were calculated.

Determination of cellular thiols

The monobromobimane assay was used to measure cellular thiol concentration. Following cell exposure to the chemicals, the cell layers were washed with PBS, and $250 \mu \mathrm{l} /$ well of $100 \mu \mathrm{M}$ monobromobimane (Sigma-Aldrich) in PBS was added at RT for 5 min in the dark. Then, the cell layers were washed with PBS and lysed with $0.1 \%$ Triton X-100 (Sigma-Aldrich) in PBS. For a positive control, cells were exposed to $100 \mu \mathrm{M}$ N-ethyl-maleimide (SigmaAldrich) for $1 \mathrm{~h}$ before the assay. Thiol adducts were measured in a fluorescence multi-well plate reader (Cytofluor) at $\lambda_{\mathrm{ex}} / \lambda_{\mathrm{em}}=360 / 460 \mathrm{~nm}$. The fluorescence of treated cells was compared with the fluorescence of untreated cells. Experiments were conducted in triplicate wells and repeated three times. Results were normalized according to the protein content and expressed as percentage of control cell values. Means \pm SD were calculated.

Determination of cellular protein content

Cellular protein concentration was determined using the BCA protein assay, according the provider's instructions (BCA Protein Assay Kit, Pierce, Rockford, USA) using bovine serum albumin as the standard. Experiments were conducted in triplicates. Means \pm SD were calculated.

\section{Glutathione-S-transferase activity}

The activity of GST in cell extracts was determined using 1-chloro-2,4-dinitrobenzene (CDNB) essentially as previously described [25]. Briefly, cells were grown for $24 \mathrm{~h}$ in 9-cm-diameter Petri dishes (BD Falcon, Basel, Switzerland) and exposed to the chemicals for $72 \mathrm{~h}$. Then, the cell layers were scrapped in cold $\mathrm{pH}$ 6.5 PBS, extracted by 4 cycles of freeze/thawing, and centrifuged at 10,000 rpm at $4^{\circ} \mathrm{C}$ for $10 \mathrm{~min}$ and the supernatants were collected. After addition of $1 \mathrm{mM}$ CDNB (Sigma-Aldrich) and $1 \mathrm{mM}$ of glutathione (GSH, Sigma-Aldrich), final concentrations, GST activity in the supernatants was determined by measuring the increase in absorbance at $340 \mathrm{~nm}$ in a multi-well plate reader (iEMS Reader) for $30 \mathrm{~min}$ at $37^{\circ} \mathrm{C}$. GST activity was expressed as nM CDNB-GSH conjugates/min/ $\mathrm{mg}$ protein. The values of enzymatic activities of treated cells were compared with enzymatic activities of untreated cells. Measurements were performed in triplicates and repeated three times. Means $\pm \mathrm{SD}$ were calculated.

\section{Western blot experiments}

Cells were grown in 9-cm-diameter Petri dishes and exposed to the chemicals for the appropriate times. After the treatments, the cell layers were washed with cold PBS and lysed in $200 \mu \mathrm{l}$ of lysis buffer $(150 \mathrm{mM} \mathrm{NaCl}, 2 \mathrm{mM}$ EDTA, $0.5 \%$ Triton X-100, $50 \mathrm{mM}$ Tris-HCl, $2 \mathrm{mM}$ vanadate, $50 \mathrm{mM} \mathrm{NaF}, \mathrm{pH} 7.2$ ) and $10 \mu \mathrm{l}$ of proteinase inhibitor cocktail (Sigma-Aldrich), scraped with a cell 
scrapper, extracted by four cycles of freeze/thawing, and centrifuged at $10,000 \mathrm{rpm}$ at $4^{\circ} \mathrm{C}$ for $10 \mathrm{~min}$. Supernatants were submitted to SDS-PAGE and transferred onto a nitrocellulose membrane (Whatman, Dassel, Germany). The membranes were blocked with $5 \%$ fat-free milk in PBS, washed in $0.05 \%$ Tween-20 (Sigma-Aldrich) in PBS, and incubated overnight at $4{ }^{\circ} \mathrm{C}$ with a polyclonal antihuman GST-P1-1 rabbit antibody (Enzo Life Sciences, Lausen, Switzerland; diluted 1:5,000 in 1\% fat-free milk $0.05 \%$ Tween-20 in PBS) and then exposed for $60 \mathrm{~min}$ to peroxidase-conjugated anti-rabbit antibody (Promega, Madison, USA; diluted 1:5,000) and visualized using chemoluminescence (ECL, GE Healthcare, Amersham, UK). Protein tyrosine phosphorylation was determined using an anti-phosphotyrosine monoclonal antibody (Transduction Laboratories, BD, Basel, Switzerland; diluted 1:2,500) and peroxidase-conjugated anti-mouse secondary antibody (Promega; diluted 1:2,500). To control for loading, the membranes were stripped by successive incubation in $0.1 \mathrm{M}$ glycine $\mathrm{pH} 2.3,1 \mathrm{M} \mathrm{NaCl}$ in PBS and $0.05 \%$ Tween 20 in PBS, blocked for $1 \mathrm{~h}$ with $5 \%$ fat-free milk in PBS and exposed to a polyclonal anti-human $\beta$-actin rabbit antibody (Sigma-Aldrich; diluted 1:5,000) for $1 \mathrm{~h}$ at RT and treated as described above.

Cell actin staining with fluorescent phalloidin

Cells were grown for $24 \mathrm{~h}$ on glass slides (Menzel-Gläser, Braunschweig, Germany). Then, the medium was changed, and chemicals diluted with complete culture medium were added at the indicated concentrations and the cells were further incubated for $72 \mathrm{~h}$. At the end of the treatment, the cell layers were washed in PBS, fixed in $4 \%$ formaldehyde for $10 \mathrm{~min}$ at RT, washed with PBS, permeabilized for 5 min in $0.1 \%$ Triton X-100 in PBS, and washed. Then, $200 \mu \mathrm{l}$ of a $1 \%$ bovine serum albumin (Sigma-Aldrich) and 2.5\% Oregon Green 488 Phalloidin (Invitrogen, $6.6 \mu \mathrm{M}$ stock solution in methanol) solution in PBS were added. After 20-min incubation at RT, the cell layers were washed with PBS, and $2 \mathrm{ml}$ of $1 \mu \mathrm{g} / \mathrm{ml} \mathrm{4} 4^{\prime}, 6^{\prime}$-diamidino-2-phenylindole (DAPI) (Roche Diagnostics, Rotkreutz, Switzerland) in PBS was added for $20 \mathrm{~min}$. Slides were washed with PBS and mounted in $20 \%$ glycerol in PBS. Fluorescence images were taken with a Zeiss Axioplan 2 Imaging microscope (Zeiss) at $400 \times$ magnification and $\lambda_{\mathrm{ex}} / \lambda_{\mathrm{em}}=$ $365 / 420 \mathrm{~nm}$ (DAPI) or $\lambda_{\mathrm{ex}} / \lambda_{\mathrm{em}}=450-490 / 515-565 \mathrm{~nm}$.

\section{Cell migration assay}

Both sides of the membrane of a two-chamber Transwell device $(6.5 \mathrm{~mm}$ diameter, $8.0-\mu \mathrm{m}$ pore size polyethylene membrane, Falcon, BD) were coated with a solution of $20 \mu \mathrm{g} / \mathrm{ml}$ collagen type IV (Sigma-Aldrich, $50 \mu \mathrm{l}$ per membrane) in $0.02 \mathrm{M}$ acetic acid for $60 \mathrm{~min}$, washed with PBS, and air-dried. Cells in $100 \mu \mathrm{l}$ complete cell culture medium were added to the upper chamber, and $600 \mu \mathrm{l}$ of cell culture medium was added to the lower chamber. After $24 \mathrm{~h}$ of culture of the cells on the membrane, the medium was changed, and chemicals diluted with complete culture medium were added at the indicated concentrations and the cells were further cultured for either 8 or $72 \mathrm{~h}$. At the end of the treatment, cells on the upper side of the membrane were removed by swiping with a damp cotton swab. The membrane was rinsed with PBS and stained for $10 \mathrm{~min}$ with $0.05 \%$ crystal violet in $1.5 \%$ glacial acetic acid (both from Sigma-Aldrich). After washing with PBS, cells of four different fields of the lower side of the membrane were counted under a microscope at a $200 \times$ magnification. Experiments were conducted in triplicate wells and repeated twice. Means \pm SD were calculated.

\section{Comet assay}

Induction of DNA strand breaks by doxorubicin and quercetin in the human mammary cells was determined using an alkaline single-gel Comet assay [26] with minor modifications. Briefly, cells were grown for $24 \mathrm{~h}$ in a 12-well plate (Corning), and then chemicals diluted with fresh complete culture medium were added at the indicated concentrations and the cells were further incubated for $72 \mathrm{~h}$. Cells were detached using trypsin-EDTA (TrypLE Express, Invitrogen), and the cell suspension $(800,000$ cells $/ \mathrm{ml}$ ) in $1 \%$ low melting point agarose (Sigma-Aldrich) was deposited on glass slides coated with $1 \%$ normal melting point agarose (Eurobio, Les Ulis, France). After $5 \mathrm{~min}$ at $4^{\circ} \mathrm{C}$ to allow solidification of the cell layer, slides were immersed in lysis buffer $(2.5 \mathrm{M} \mathrm{NaCl}, 100 \mathrm{mM}$ EDTA, $10 \mathrm{mM}$ Tris-base, $1 \%$ Triton $\mathrm{X}-100, \mathrm{pH} 10.0$ ) for $1 \mathrm{~h}$ at $4^{\circ} \mathrm{C}$, and then a 40 -min unwinding process at $4^{\circ} \mathrm{C}$ and electrophoresis at $300 \mathrm{~mA}$ and $25 \mathrm{~V}$ for $30 \mathrm{~min}$ were performed, both under alkaline conditions $(300 \mathrm{mM}$ $\mathrm{NaOH}, 1 \mathrm{mM}$ EDTA, pH 13.0). Following washing with cold PBS and cold nanopure water, slides were stained with $1 \mu \mathrm{g} / \mathrm{ml}$ DAPI (Roche) in PBS. Analysis of Comet appearance was carried out with a Zeiss Axioplan 2 Imaging microscope at a $200 \times$ magnification and $\lambda_{\mathrm{ex}} /$ $\lambda_{\mathrm{em}}=365 / 420 \mathrm{~nm}$. For each experiment, 100 cells were analyzed twice randomly per treatment, using the Comet assay image analysis software (Comet Visual, University of Oslo, Faculty of Medicine, Department of Nutrition, Oslo, Norway). Damaged cells were classified into four classes according to the comet tail length, using the visual scoring approach [27]. Results were expressed as percentage of damaged DNA in treated cells compared with nontreated cells. Experiments were conducted in duplicates and repeated twice. Means \pm SD were calculated. 
Statistical analysis

Results were subjected to computer-assisted statistical analysis using the ANOVA one-way analysis of variance and the Tukey-Kramer single-step multiple comparison procedure as a post test. Differences of $P<0.05$ were considered significant. For all experiments and each cell line, treatment effect was first evaluated in treated versus untreated cells, and then the different cell lines were compared between them.

\section{Results}

For these experiments, we selected two human breast cancer cell lines, MDA-MB-231 cells that are highly aggressive and MCF-7 cells that are less aggressive, and a breast- derived cell line, MCF-10A cells that are non-tumoral [27]. First, we determined the sensitivity of the three human breast-derived cells to doxorubicin by evaluating their survival and synthesis of DNA and proteins after a 3-day exposure to the drug (Fig. 1A). Doxorubicin dose dependently reduced cell survival in all three cells (Fig. 1Aa). From these results, we selected two doxorubicin concentrations for further experiments, $100 \mathrm{nM}$, representing the mean plasma concentration of doxorubicin in patients under chemotherapy [3], and a tenfold lower concentration, $10 \mathrm{nM}$. At $100 \mathrm{nM}$ doxorubicin, DNA synthesis was abolished in all three cells, whereas at $10 \mathrm{nM}$, the decrease in DNA synthesis was more apparent in MDA-MB-231 and MCF-10A cells than in MCF-7 cells (Fig. 1Ab). Cells were dose dependently sensitive to the drug for inhibition of protein synthesis, but at a lesser level than of DNA synthesis (Fig. 1Ac). Then, we performed a time-course evaluation of
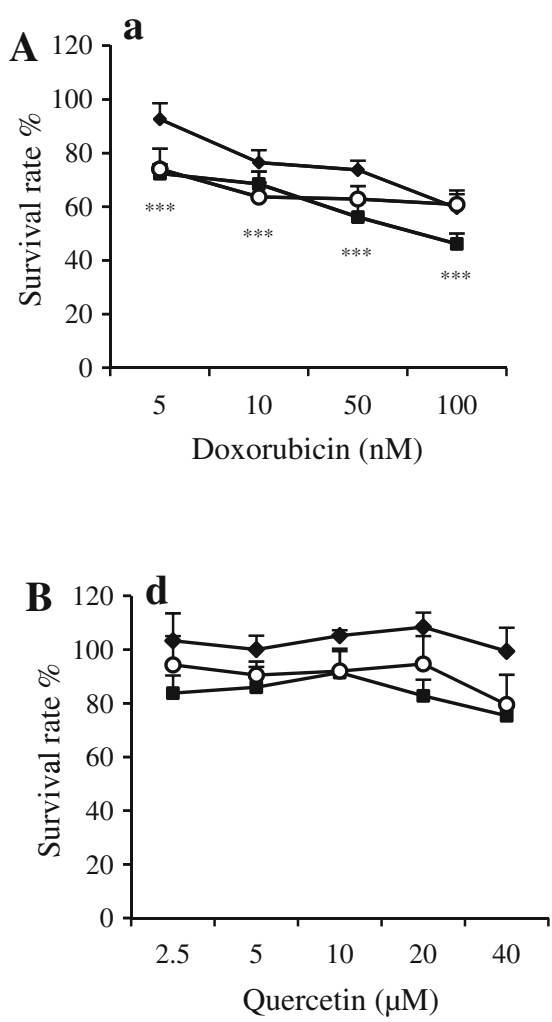
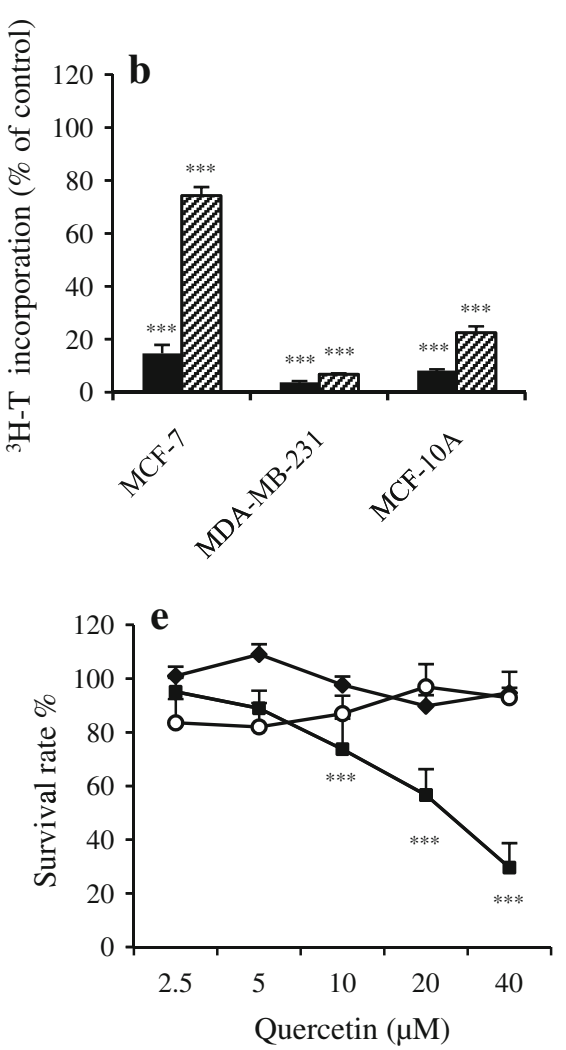
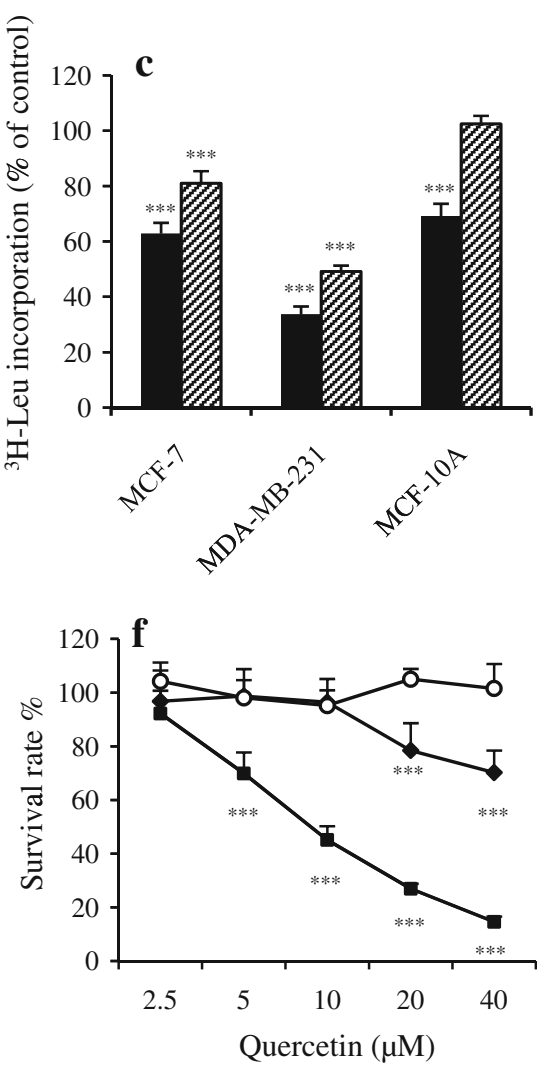

Fig. 1 Effect of doxorubicin and quercetin on cell survival and DNA and protein synthesis. A, $a$ Human MDA-MB-231 and MCF-7 breast cancer cells and non-tumoral MCF-10A breast-derived cells were exposed for $72 \mathrm{~h}$ to $a$ increasing concentrations of doxorubicin $(5,10$, 50 , and $100 \mathrm{nM}$ ) and then the MTT assay was performed: MDA-MB231 cells (filled square), MCF-7 cells (filled diamond), MCF-10A cells (open circle); $b$ doxorubicin (DOX) $(100 \mathrm{nM}$, black bars or $10 \mathrm{nM}$, stripped bars), and then ${ }^{3} \mathrm{H}$-thymidine incorporation $\left({ }^{3} \mathrm{H}-\mathrm{T}\right)$ was performed to evaluate DNA synthesis; and $c$ doxorubicin (DOX) $\left(100 \mathrm{nM}\right.$, black bars or $10 \mathrm{nM}$, stripped bars), and then ${ }^{3} \mathrm{H}$-leucine incorporation $\left({ }^{3} \mathrm{H}-\mathrm{Leu}\right)$ was performed to evaluate protein synthesis.
Results are the means \pm SD of quadruplicates of two independent experiments. Treated cells were compared with untreated cells using a Student's $t$ test: $* P<0.05$; $* * P<0.01 ; * * * P<0.001$. B Human MDA-MB-231 (filled square) and MCF-7 breast cancer cells (filled diamond) and non-tumoral MCF-10A breast-derived cells (open circle) were exposed to increasing concentrations of quercetin for $24 \mathrm{~h}(d), 48 \mathrm{~h}(e)$, or $72 \mathrm{~h}(f)$, and then the MTT assay was performed. Results are the means \pm SD of quadruplicates of two independent experiments. Treated cells were compared with untreated cells using a Student's $t$ test: $* P<0.05 ; * * P<0.01 ; * * * P<0.001$ 
cell sensitivity to quercetin (Fig. 1B). Cell survival was little affected by quercetin after $24 \mathrm{~h}$ (Fig. 1Bd); however, after 48 and $72 \mathrm{~h}$, quercetin dose dependently decreased survival in both tumor cells, MDA-MB-231 cells responding more and more rapidly than MCF-7 cells to the drug (Fig. 1Be, Bf). From this information, we selected 5 and $10 \mu \mathrm{M}$ quercetin corresponding to slightly lower and higher quercetin concentration compared with the $\mathrm{IC}_{50}(9 \mu \mathrm{M})$ of quercetin for the most sensitive cells.

For further drug combination studies, we exposed the cells for $72 \mathrm{~h}$ to each drug alone or to combinations of 10 $\mathrm{nM}$ and $100 \mathrm{nM}$ doxorubicin and $5 \mu \mathrm{M}$ and $10 \mu \mathrm{M}$ quercetin, respectively. First, we determined the sensitivity of the three human breast-derived cells to drug combinations by evaluating their survival and the synthesis of DNA and proteins after a 3-day cell exposure to the drug (Fig. 2). In MCF-7 and MCF-10A cells, quercetin was less efficient than doxorubicin and did not enhance doxorubicin cytotoxic effects (Fig. 2A). In MDA-MB-231 cells, $10 \mu \mathrm{M}$ quercetin was as cytotoxic as $100 \mathrm{nM}$ doxorubicin and enhanced doxorubicin effects, the combination of $10 \mathrm{nM}$ doxorubicin and $10 \mu \mathrm{M}$ quercetin being as cytotoxic as $100 \mathrm{nM}$ doxorubicin. Quercetin alone dose dependently inhibited DNA synthesis more in MDA-MB-231 cells than in the other cells and in combination with doxorubicin enhanced doxorubicin effects in MCF-7 cells (Fig. 2B). Quercetin dose dependently inhibited protein synthesis and in combination enhanced doxorubicin effects in tumor cells, but not in non-tumoral cells (Fig. 2C).

Then, we determined whether oxidative stress may be involved in these effects by evaluating ROS production by cells, thiol content in cells or GST activity and expression by cells. No changes in ROS production by either of the three cell lines were observed following cell exposure to doxorubicin and quercetin, or their combination for 24 or $72 \mathrm{~h}$ (data not shown). Quercetin did not modulate cellular thiols levels in MCF-7 cells and dose dependently increased cellular thiol levels in MDA-MB-231 and MCF$10 \mathrm{~A}$ cells; however, quercetin could compensate for doxorubicin-induced decreased levels of cellular thiols in non-tumoral cells (Fig. 3A). MCF-7 cells did not express GST activity or GST-P1-1 protein (results not shown), confirming previous information [28], and GST expression was higher in MCF-10A than in MDA-MB-231 cells. Only in MDA-MB-231 cells did quercetin, but not doxorubicin, decreased GST activity (Fig. 3B), but not GST-P1-1 protein determined by western blot (results not shown).

We also determined whether quercetin may modulate cellular tyrosine phosphorylation pathways and druginduced DNA damage in human mammary tumor and nontumoral cells. In MDA-MB-231 cells, quercetin decreased tyrosine phosphorylation of a major $75-\mathrm{kDa}$ protein that was maintained in combination with doxorubicin. In
MCF-10A cells, quercetin increased tyrosine phosphorylation of a major 55-kDa protein which was also maintained in combination with doxorubicin (Fig. 4A). No major band of tyrosine phosphorylated proteins was found in MCF-7 cells (not shown). In all three cells, doxorubicin induced high amount of DNA strand breaks, whereas quercetin alone did not. Combination of quercetin with doxorubicin reduced DNA damage more in non-tumoral cells than in tumor cells (Fig. 4B).

Then, we evaluated whether the migratory potential of tumor cells may be affected more by drug combinations than each drug alone, either after short-term exposure $(8 \mathrm{~h})$ or long-term exposure (72 h) (Fig. 5). Both drugs and their combination significantly diminished breast tumor cell migration, and quercetin additively potentiated doxorubicin effects (Fig. 5 upper panels). However, the migratory potential of MDA-MB-231 cells was higher than the migratory potential of MCF-7 cells at both times (Fig. 5 lower panels). Following cell exposure to the drugs or their combinations, cytoskeletal actin expression and cellular localization was evaluated using fluorescent phalloidin. In MCF-7 cells (Fig. 6A), doxorubicin did not interfere with cytoskeletal actin, while quercetin induced a weak fragmentation of actin at the cell membrane, which was enhanced by drug combination. In MDA-MB-231 cells (Fig. 6B), doxorubicin induced a decrease in the ratio of cytoplasm-to-nucleus sizes, whereas quercetin as single agent as well as its combination with doxorubicin induced cell polynucleation, a never-reported finding (Fig. 6B, arrowheads). The drugs either as single agents or their combination did not modify cytoskeletal actin of MCF10A cells (Fig. 6C). Doxorubicin induced heterogeneity of the size of the nuclei in all three cells.

\section{Discussion}

Our aims are to evaluate new chemotherapeutic combinations based on the anthracycline doxorubicin, an essential component of combination chemotherapies for the treatment of breast cancer, however, displaying toxicity for normal cells [3, 4]. Most breast cancer patients with advanced disease treated with present combination therapies have only temporary responses to treatment, associated with reduced quality of life due to the side effects of the therapies. Thus, improved therapeutic regimens able to potentiate doxorubicin effects, allowing decreasing the dose of this agent, together with protecting non-tumoral cells against the non-specific cytotoxic effects of doxorubicin for these cells, are needed to improve treatment of breast cancer patients. In vitro and in animal models of cancer, several natural products including quercetin improved the therapeutic index of doxorubicin [22-24]. In 

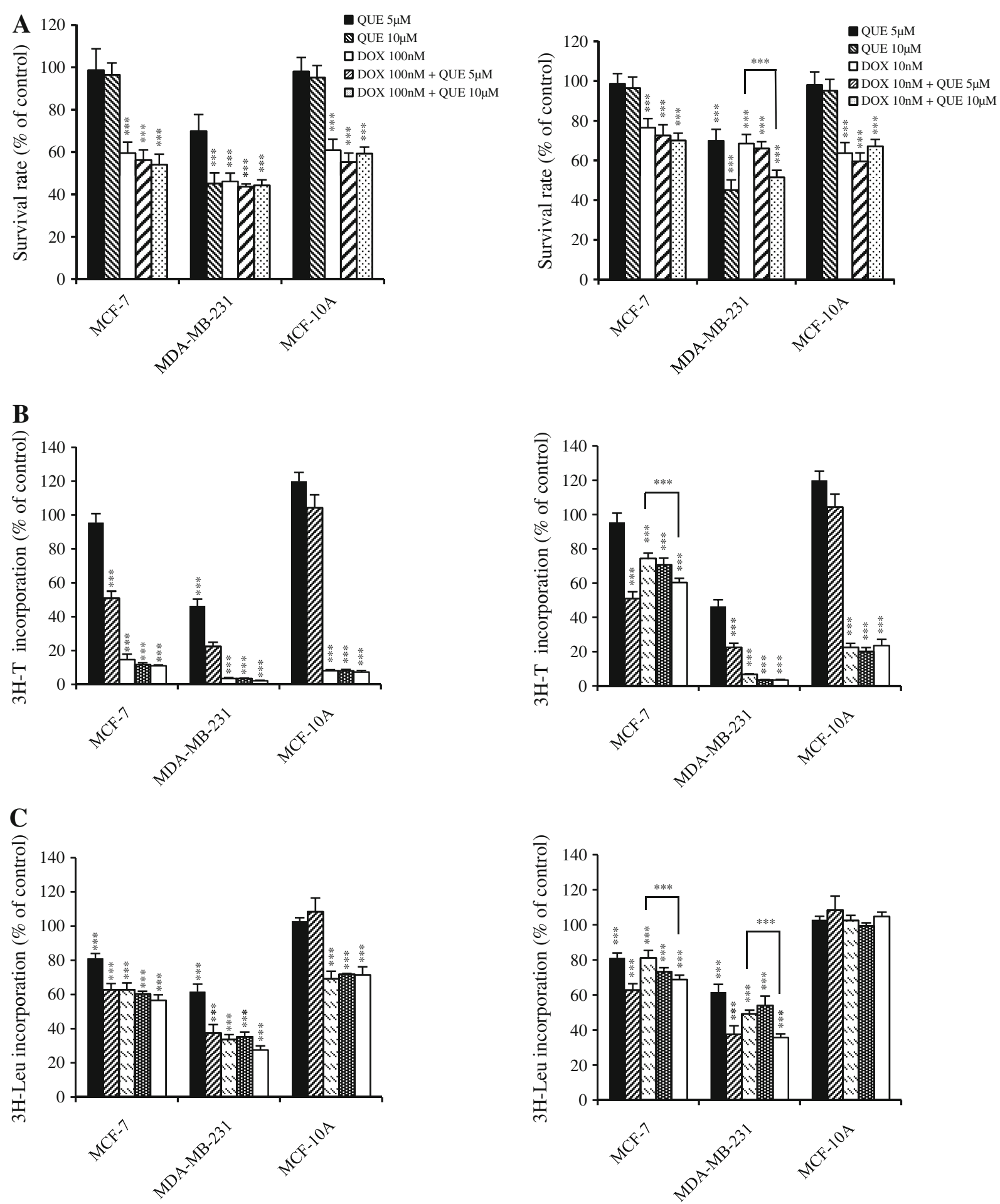

Fig. 2 Effect of a 3-day exposure to doxorubicin-quercetin combination on cell survival and DNA and protein synthesis. Human MDAMB-231 and MCF-7 breast cancer cells and non-tumoral MCF-10A breast-derived cells were exposed to doxorubicin (DOX) $(100 \mathrm{nM}$, left panels, or $10 \mathrm{nM}$, right panels) and quercetin (QUE) $(5$ or $10 \mu \mathrm{M})$ as single agents or in combination for $72 \mathrm{~h}$, then A the MTT test to

measure cell survival or $\mathbf{B}{ }^{3} \mathrm{H}$-thymidine incorporation $\left({ }^{3} \mathrm{H}-\mathrm{T}\right)$ to quantify DNA synthesis, or $\mathbf{C}^{3} \mathrm{H}$-leucine incorporation $\left({ }^{3} \mathrm{H}-\mathrm{Leu}\right)$ to quantify protein synthesis was performed. Results are the means $\pm \mathrm{SD}$ of quadruplicates of two independent experiments. Treated cells were compared with untreated cells using a Student's $t$ test: $* P<0.05 ; * * P<0.01 ; * * * P<0.001$ 

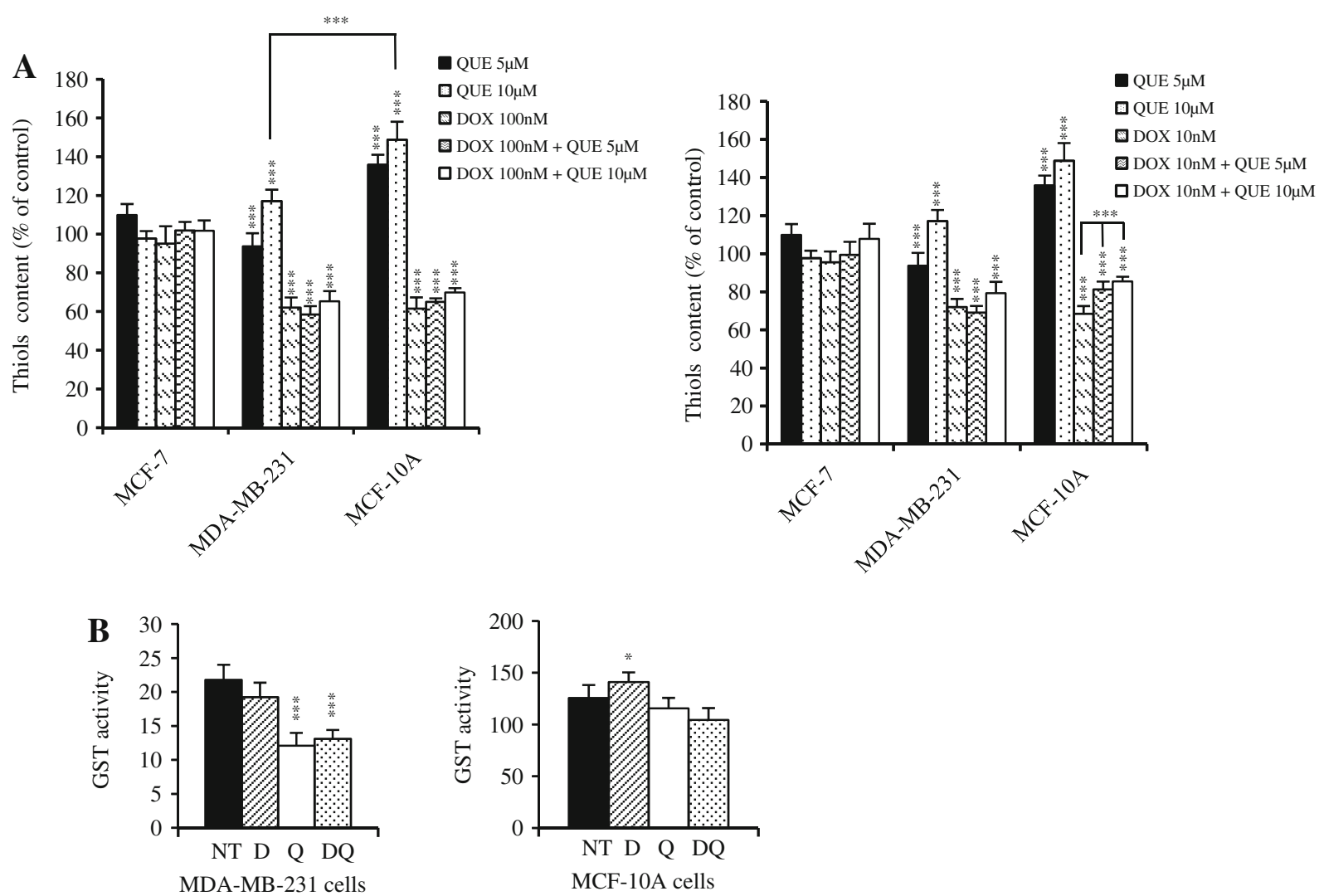

Fig. 3 Effects of a 3-day exposure to doxorubicin, quercetin or doxorubicin-quercetin combinations on cellular thiol content and GST activity. A Human MDA-MB-231 and MCF-7 breast cancer cells and non-tumoral MCF-10A breast-derived cells were exposed for $72 \mathrm{~h}$ to either doxorubicin (DOX) $(100 \mathrm{nM}$, left panel or $10 \mathrm{nM}$, right panel) or quercetin $(5$ or $10 \mu \mathrm{M})$ as single agents or in combination, and then the thiol content of cell lysates was determined using a monobromobimane assay. Results are the means \pm SD of triplicates of three independent experiments. Treated cells were compared with untreated cells using a Student's $t$ test: $* P<0.05$;

murine models of cancer, combination of dietary quercetin and intratumoral injection of doxorubicin was able to synergistically reduce tumor volume and metastatic spread [23]. Quercetin was previously shown to be able to also reduce in vitro the toxicity of doxorubicin by inhibiting the catalytic activity of enzymes involved in doxorubicin biotransformation [3, 24]. Therefore, we evaluated some of the effects and cellular mechanisms of doxorubicin-quercetin combination in human breast cancer cells of increasing aggressiveness, the poorly metastatic MCF-7 cells and the highly metastatic MDA-MB-231 cells compared with human non-tumoral MCF-10A mammary cells [27]. In human plasma, the peak and the steady-state concentrations of doxorubicin are $5 \mu \mathrm{M}$ and $25-250 \mathrm{nM}$, respectively $[3,29]$. Therefore, for these experiments, we selected doses of doxorubicin representing relevant plasma levels in patients treated with doxorubicin, and a tenfold lower dose to evaluate combination effects.
$* * P<0.01 ; * * * P<0.001$. B Human MDA-MB-231 breast cancer cells (left panel) or MCF-10A non-tumoral breast-derived cells (right panel) were exposed to $10 \mathrm{nM}$ doxorubicin (DOX), $10 \mu \mathrm{M}$ quercetin, or a combination of both for $72 \mathrm{~h}$, and then GST activity (nM of CDNB-GSH $/ \mathrm{min} / \mathrm{mg}$ of proteins) was evaluated in cell extracts. Results are the means \pm SD of triplicates of three independent experiments. Treated cells were compared with untreated cells using a Student's $t$ test: $* P<0.05 ; * * P<0.01 ; * * * P<0.001$. CDNB, 1-chloro-2,4-dinitrobenzene; $N T$ non-treated

The mechanisms of action of anthracyclines in cancer cells are controversial. Doxorubicin is thought to bind and cross-link DNA and to intercalate between bases and thus to inhibit DNA, RNA, and protein synthesis. Doxorubicin inhibits topoisomerase II, essential enzymes that act by introducing or removing DNA superhelical tensions, tying or untying DNA knots and catenating or decatenating circular DNA [29, 30], thus initiating DNA damage and cell apoptosis. Type I DNA topoisomerases introduce transient single-strand DNA breaks, while type II DNA topoisomerases introduce transient DNA double-strand breaks. Doxorubicin inhibits the topoisomerase II by locking onto the $5^{\prime}$-end of the DNA molecule, inducing DNA breaks [29]. Tumor cells that are resistant to the anthracyclines have reduced levels or altered activity of this enzyme, with a concomitant reduction of DNA strand breaks. Doxorubicin has been shown to induce the generation of free radicals and oxidative DNA damage in both malignant and 
A

MDA-MB-231
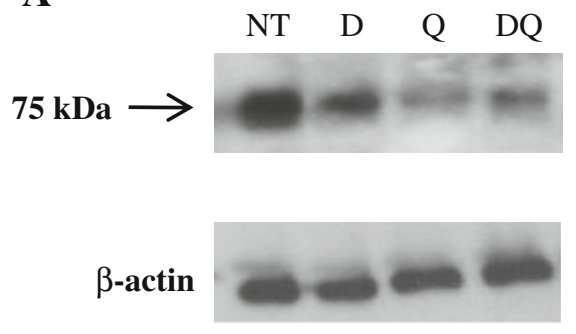

MCF-10A

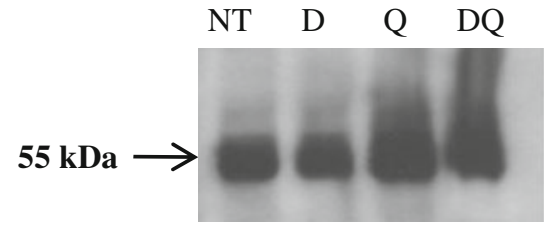

$\beta$-actin

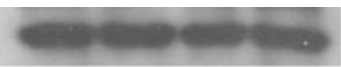

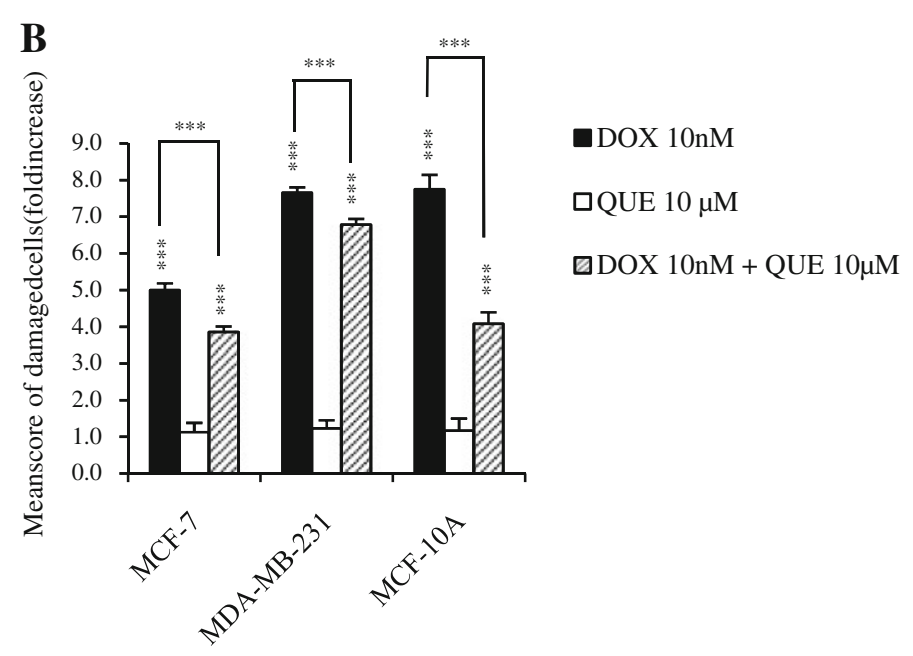

Fig. 4 Effects of doxorubicin and quercetin on cellular protein tyrosine phosphorylation and DNA strand breaks. A Human MDAMB-231 breast cancer cells (left panel) or MCF-10A non-tumoral breast-derived cells (right panel) were exposed to $10 \mathrm{nM}$ doxorubicin (DOX), $10 \mu \mathrm{M}$ quercetin, or a combination of both for $72 \mathrm{~h}$, and then cell protein phosphorylation was determined by western blot in cell extracts using a phosphotyrosine protein-specific antibody. B Human MCF-7, MDA-MB-231 breast cancer cells and non-tumoral breast-

non-malignant cells [3, 4, 29-31], resulting in lipid peroxidation and altered levels of GSH or of the enzymes of the GSH redox pathway [19]. Other possible mechanisms may also explain the cytotoxicity of anthracyclines, such as interference with microtubule polymerization and cell cytoskeleton, or modulation of PKC $\delta$ activity [29, 32]. Alternatively to cell death, anthracyclines can induce growth arrest in the $\mathrm{G}_{2}$ phase of the cell cycle [3].

As expected from previous information, doxorubicin as a single agent dose dependently reduced cell survival of all three human breast-derived cells, tumor cells as well as non-tumoral cells. Doxorubicin dose dependently also reduced DNA and protein synthesis and this reduction was cell type dependent. Previous studies have shown that quercetin dose dependently suppressed growth, DNA, RNA, and protein synthesis of breast cancer cells by increasing the expression of connexin proteins and modifying cell morphology [8, 33]. As a single agent, quercetin dose dependently decreased tumor cell survival of both MCF-7 and MDA-MB-231 cells, the most aggressive cells derived MCF-10A cells were exposed for $72 \mathrm{~h}$ to $10 \mathrm{nM}$ doxorubicin (DOX), $10 \mu \mathrm{M}$ quercetin (QUE), or their combinations, and then the Comet assay was performed to evaluate DNA strand breaks. Results are expressed as the fold-increase score of damaged DNA of treated cells compared with untreated cells and are the means $\pm S D$ of duplicates of two independent experiments. Treated cells were compared with untreated cells using a Student's $t$ test: $* P<0.05$; $* * P<0.01 ; * * * P<0.001$

responding more than the less aggressive cells and the nontumoral cells. Quercetin dose dependently also inhibited DNA and protein synthesis, enhancing doxorubicin effects in tumor cells, but not in non-tumoral cells. In agreement with our results, previous reports have shown that quercetin can interfere with cancer cell metabolism and proliferation [9, 34-36]. In addition, we show that quercetin enhanced doxorubicin cytotoxic effects in tumor cells but that the non-specific effects are much less marked for non-tumoral than for tumor cells. The anticancer effects of quercetin have been attributed to the inhibition of enzymes that activates carcinogenesis, antioxidant activity, modification of signal transduction pathways and interaction with receptors and other proteins [8, 36-38]. In our experiments, no changes in ROS production by either of the three cells were observed; however, quercetin was able to compensate for doxorubicin-induced decrease in cellular thiols, in particular in non-tumoral cells, without important modification of GST activity or GST-P1-1 expression. Moreover, quercetin modified the tyrosine phosphorylation of cellular 
Fig. 5 Effects of doxorubicin, quercetin, and doxorubicinquercetin combination on cell migration through a collagen IV layer. Human MDA-MB-231 and MCF-7 breast cancer cells were seeded on the upper chambers of collagen-coated membranes of Transwell inserts and cultured for either $8 \mathrm{~h}$ (left panels) or $72 \mathrm{~h}$ (right panels) in the presence of $10 \mathrm{nM}$ doxorubicin (DOX), $10 \mu \mathrm{M}$ quercetin (QUE), or their combinations. Then, cells that had migrated through the membranes were counted in four different viewing fields at $200 \times$ magnification. Results are the means $\pm \mathrm{SD}$ of triplicates of two independent experiments. Treated cells were compared with untreated cells using a Student's $t$ test: $* P<0.05 ; * * P<0.01$; $* * * P<0.001$ (upper panels). The mean number of migrated cells is provided to directly compare the migratory potential of both tumor cell lines (lower panels)
8 hours

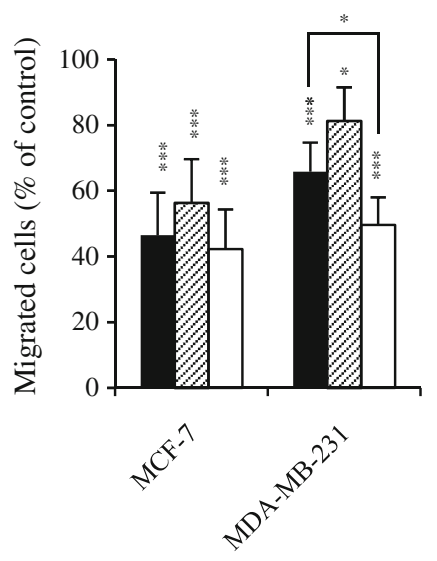

72 hours

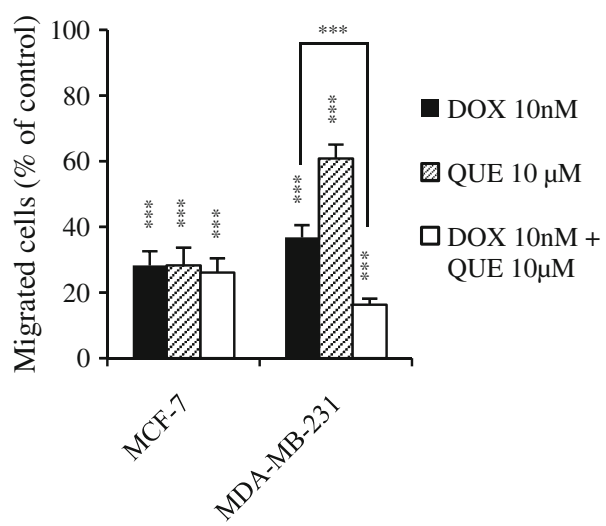

\section{Mean number of cells per viewing fields}

$\begin{array}{lrlr}\text { MCF-7: } & 12 \pm 1 & \text { MCF-7: } & 46 \pm 6 \\ \text { MCF-7 (Q): } & 7 \pm 2 & \text { MCF-7 (Q): } & 13 \pm 3 \\ \text { MCF-7 (D): } & 6 \pm 1 & \text { MCF-7 (D): } & 13 \pm 2 \\ \text { MCF-7 (DQ): } & 5 \pm 2 & \text { MCF-7 (DQ): } & 12 \pm 2 \\ & & & \\ \text { MDA-MB-231: } & 21 \pm 4 & \text { MDA-MB-231: } & 424 \pm 21 \\ \text { MDA-MB-231 (Q): } & 17 \pm 3 & \text { MDA-MB-231 (Q): } 258 \pm 18 \\ \text { MDA-MB-231 (D): } & 14 \pm 3 & \text { MDA-MB-231 (D): } & 156 \pm 16 \\ \text { MDA-MB-231 (DQ): } & 10 \pm 3 & \text { MDA-MB-231 (DQ): } & 69 \pm 8\end{array}$

proteins differently in tumor cells than in non-tumoral cells and these changes were maintained in combination with doxorubicin, suggesting a major role of quercetin in protein kinase pathways in tumor cells and non-tumoral cells. Kinase pathways, such as the mitogen-activated protein kinase, 1-phosphatidylinositol kinase, and the src protein kinase pathways, are also cellular targets of quercetin [16, 39-41]. In breast cancer cells, quercetin was previously shown to block the translocation of the $\operatorname{PKC} \delta$ protein from the cytosol to the membrane inhibiting the transduction of the PKC $\delta$ signaling pathway [42]. We show that quercetin potentiated doxorubicin effects in diminishing breast tumor cell migration, and in cell-selectively modifying doxorubicin effects on cytoskeletal actin, suggesting an effect on cell cytoskeleton assembly, cytoplasm size, and cell polynucleation, a up to now never-reported effect of quercetin. Combination of quercetin with doxorubicin reduced DNA strand breaks and damage more in non-tumoral cells than in tumor cells, thus suggesting a protective role of quercetin.

In summary, our results have shown that combining doxorubicin with quercetin may be very interesting for chemotherapy of human breast cancer, and possibly of other human cancers based on doxorubicin, since this molecule can enhance the toxic effects of doxorubicin in breast cancer cells and reduce the side effects of doxorubicin in non-tumoral cells. This combination also allows reaching an anticancer efficacy with lower doses of doxorubicin comparable to the effect achieved with higher doses, and thus decreasing cytotoxic effects of high doses of doxorubicin for normal cells. We hypothesize that the selectivity of quercetin for highly aggressive cancer cells is due to its properties as a tyrosine protein kinase inhibitor. However, the limitation of using quercetin in human therapy is the high dose of this agent necessary to achieve efficacy. Thus, it will be necessary to better understand the molecular and cellular mechanisms of quercetin and its chemical characteristics, which may be improved to develop new cancer-specific drugs.

Acknowledgments We want to thank Dr. C. Brisken for the kind gift of MCF-10A cells, Dr. F. Schmitt for very helpful discussions and comments, Ms. C. Chapuis Bernasconi for excellent technical assistance, and the European Community FP7 project "NanoTest" (grant No 2007-201335) for financial support (to BHK and LJJ). The results shown here are part of Master thesis work of E. Idrizi and D. Staedler at the University of Lausanne (UNIL). 

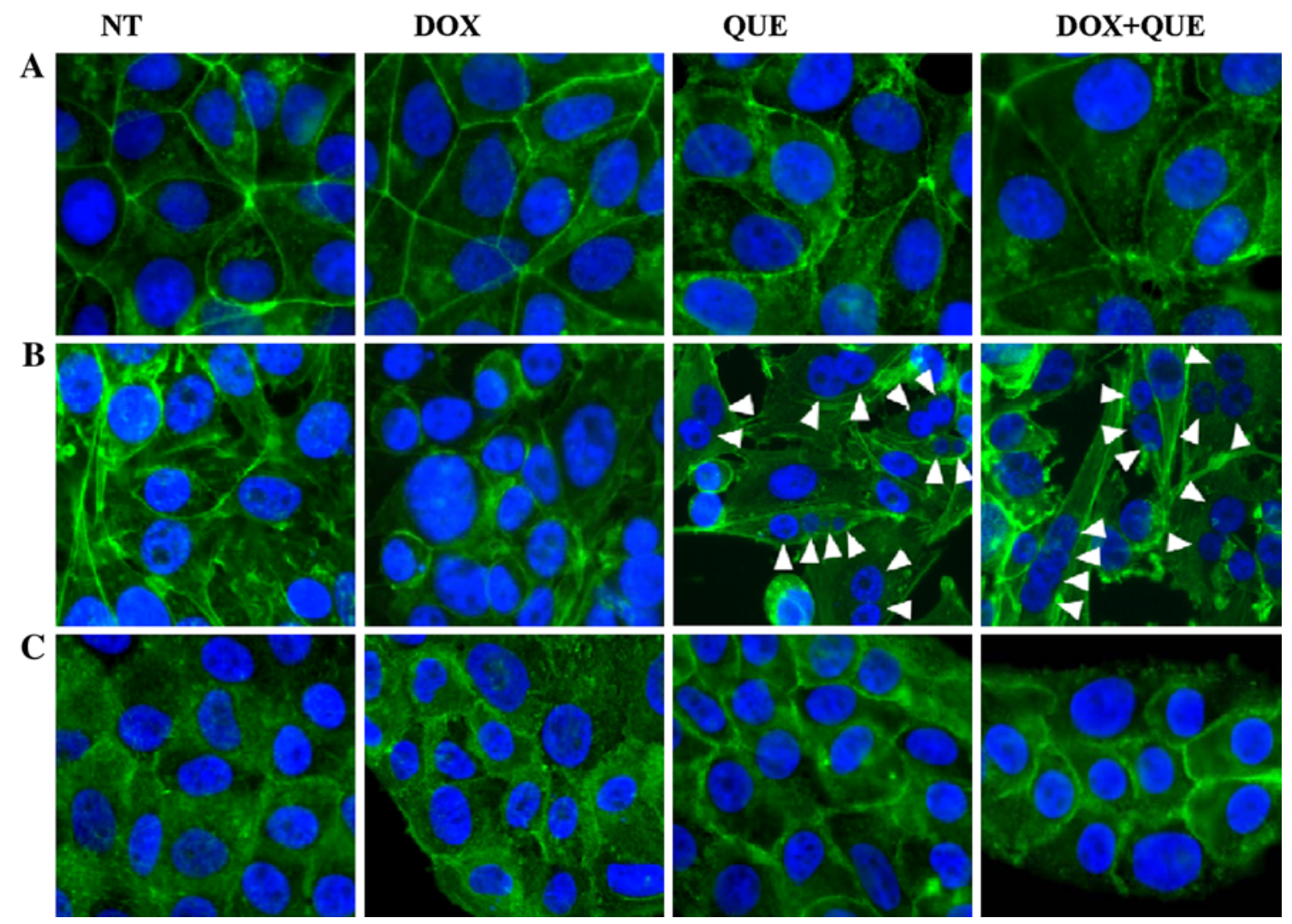

Fig. 6 Evaluation of the effect of a 3-day exposure to doxorubicin, quercetin or their combination on cytoskeletal actin expression and nuclear ploidy of human breast cells. Human MCF-7 (A), MDA-MB231 (B), or MCF-10A (C) cells were exposed to doxorubicin, quercetin, or their combinations for $72 \mathrm{~h}$, and then cells were fixed

and stained with fluorescent phalloidin as an actin probe (green) and DAPI as a nuclear probe (blue). NT: non-treated cells; $D O X: 10 \mathrm{nM}$ doxorubicin; QUE: $10 \mu \mathrm{M}$ quercetin; $D O X+Q U E: 10 \mathrm{nM}$ doxorubicin plus $10 \mu \mathrm{M}$ quercetin. Arrowheads: polynucleated cells

Conflict of interest The authors declare no conflict of interest.

\section{References}

1. Hortobagyi GN (1998) Treatment of breast cancer. N Engl J Med 339:974-984

2. Andreetta C, Minisini AM, Miscoria M, Puglisi F (2010) Firstline chemotherapy with or without biologic agents for metastatic breast cancer. Crit Rev Oncol Hematol 76:99-111

3. Minotti G, Menna P, Salvatorelli E, Cairo G, Gianni L (2004) Anthracyclines: molecular advances and pharmacologic developments in antitumor activity and cardiotoxicity. Pharmacol Rev 56:185-229

4. Gajewski E, Gaur S, Akman SA, Matsumoto L, van Balgooy JN, Doroshow JH (2007) Oxidative DNA base damage in MCF-10A breast epithelial cells at clinically achievable concentrations of doxorubicin. Biochem Pharmacol 73:1947-1956

5. Adlercreutz H, Mousavi Y, Hockerstedt K (1992) Diet and breast cancer. Acta Oncol 31:175-181

6. Ferry DR, Smith A, Malkhandi J, Fyfe DW, deTakats PG, Anderson D, Baker J, Kerr DJ (1996) Phase I clinical trial of the flavonoid quercetin: pharmacokinetics and evidence for in vivo tyrosine kinase inhibition. Clin Cancer Res 2:659-668

7. Moon YJ, Wang L, DiCenzo R, Morris ME (2008) Quercetin pharmacokinetics in humans. Biopharm Drug Dispos 29:205-217

8. Rodgers EH, Grant MH (1998) The effect of the flavonoids, quercetin, myricetin and epicatechin on the growth and enzyme activities of MCF7 human breast cancer cells. Chem Biol Interact 116:213-228

9. Paliwal S, Sundaram J, Mitragotri S (2005) Induction of cancerspecific cytotoxicity towards human prostate and skin cells using quercetin and ultrasound. Br J Cancer 92:499-502

10. Wang L, Tu YC, Lian TW, Hung JT, Yen JH, Wu MJ (2006) Distinctive antioxidant and antiinflammatory effects of flavonols. J Agric Food Chem 54:9798-9804

11. Bach A, Bender-Sigel J, Schrenk D, Flugel D, Kietzmann K (2010) The antioxidant quercetin inhibits cellular proliferation via HIF-1-dependent induction of p21WAF. Antioxid Redox Signal 13:437-448

12. Kawahara T, Kawaguchi-Ihara N, Okuhashi Y, Itoh M, Nara N, Tohda S (2009) Cyclopamine and quercetin suppress the growth of leukemia and lymphoma cells. Anticancer Res 29:4629-4632

13. Caltagirone S, Rossi C, Poggi A, Ranelletti FO, Natali PG, Brunetti M, Aiello FM, Piantelli M (2000) Flavonoids apigenin and quercetin inhibit melanoma growth and metastatic potential. Int J Cancer 87:595-600

14. Hsieh TC, Wu JM (2009) Targeting CWR22Rv1 prostate cancer cell proliferation and gene expression by combinations of the phytochemicals EGCG, genistein and quercetin. Anticancer Res 29:4025-4032

15. Ferraresi R, Troiano L, Roat E, Lugli E, Nemes E, Nasi M, Pinti M, Fernandez MI, Cooper EL, Cossarizza A (2005) Essential requirement of reduced glutathione (GSH) for the anti-oxidant effect of the flavonoid quercetin. Free Radic Res 39:1249-1258 
16. Lo HW, Ali-Osman F (2007) Genetic polymorphism and function of glutathione S-transferases in tumor drug resistance. Curr.Opin. Pharmacol. 7:367-374

17. Tsuchida S, Sato K (1992) Glutathione transferases and cancer. Crit Rev Biochem Mol Biol 27:337-384

18. Hayes JD, Flanagan JU, Jowsey IR (2005) Glutathione transferases. Ann Rev Pharmacol Toxicol 45:51-88

19. Perquin M, Oster T, Maul A, Froment N, Untereiner M, Bagrel D (2000) The glutathione-related detoxification pathway in the human breast: a highly coordinated system disrupted in the tumour tissues. Cancer Lett 158:7-16

20. Akbas SH, Timur M, Ozben T (2005) The effect of quercetin on topotecan cytotoxicity in MCF-7 and MDA-MB 231 human breast cancer cells. J Surg Res 125(125):49-55

21. Schlachterman A, Valle F, Wall KM, Azios NG, Castillo L, Morell L, Washington AV, Cubano LA, Dharmawardhane SF (2008) Combined resveratrol, quercetin, and catechin treatment reduces breast tumor growth in a nude mouse model. Transl Oncol 1:19-27

22. Du G, Lin H, Wang M, Zhang S, Wu X, Lu L, Ji L, Yu L (2010) Quercetin greatly improved therapeutic index of doxorubicin against 4T1 breast cancer by its opposing effects on HIF-1alpha in tumor and normal cells. Cancer Chemother Pharmacol 65:277-287

23. Du G, Lin H, Yang Y, Zhang S, Wu X, Wang M, Ji L, Lu L, Yu L, Han G (2010) Dietary quercetin combining intratumoral doxorubicin injection synergistically induces rejection of established breast cancer in mice. Int Immunopharmacol 10:819-826

24. Vaclavikova R, Kondrova E, Ehrlichova M, Boumendjel A, Kovar J, Stopka P, Soucek P, Gut I (2008) The effect of flavonoid derivatives on doxorubicin transport and metabolism. Bioorg Med Chem 16:2034-2042

25. Juillerat-Jeanneret L, Chapuis Bernasconi C, Bricod C, Gros S, Trepey S, Benhattar J, Janzer RC (2008) Heterogeneity of human glioblastoma: glutathione-S-transferase and methylguanine methyl transferase. Cancer Invest 26:597-608

26. Collins AR (2004) The comet assay for DNA damage and repair: principles, applications, and limitations. Mol Biotechnol 26:249-261

27. Nagaraja GM, Othman M, Fox BP, Alsaber R, Pellegraino CM, Zeng Y, Khanna R, Tamburini P, Swaroop A, Kandpal RP (2006) Gene expression signatures and biomarkers of noninvasive and invasive breast cancer cells: comprehensive profiles by representational difference analysis, microarrays and proteomics. Oncogene 25:2328-2338

28. Wang K, Ramji S, Bhathena A, Lee C, Riddick DS (1999) Glutathione S-transferase in wild-type and doxorubicin-resistant MCF-7 human breast cancer cell lines. Xenobiotica 29:155-170

29. Gewirtz DA (1999) A critical evaluation of the mechanisms of action proposed for the antitumor effects of the anthracycline antibiotics adriamycin and daunorubicin. Biochem Pharmacol 57:727-741

30. Topcu Z (2001) DNA topoisomerases as targets for anticancer drugs. J Clin Pharm Ther 26:405-416

31. Momparler RM, Karon M, Siegel SE, Avila F (1976) Effect of adriamycin on DNA, RNA, and protein synthesis in cell-free systems and intact cells. Cancer Res 36:2891-2895

32. Diaz Bessone MI, Berardi DE, Campodonico PB, Todaro LB, Lothstein L, Bal de Kier Joffe ED, Urtreger AJ (2010) Involvement of PKC delta (PKCdelta) in the resistance against different doxorubicin analogs. Breast Cancer Res Treat (in press)

33. Conklin CMJ, Bechberger JF, MacFabe D, Guthrie N, Kurowska EM, Naus CC (2007) Genistein and quercetin increase connexin 43 and suppress growth of breast cancer cells. Carcinogenesis 28:93-100

34. van Zanden JJ, Ben Hamman $\mathrm{O}$, van Iersel ML, Boeren S, Cnubben NH, Lo Bello M, Vervoort J, van Bladeren PJ, Rietjens IM (2003) Inhibition of human glutathione S-transferase P1-1 by the flavonoid quercetin. Chem Biol Interact 145:139-148

35. Gutzeit HO, Henker Y, Kind B, Franz A (2004) Specific interactions of quercetin and other flavonoids with target proteins are revealed by elicited fluorescence. Biochem Biophys Res Commun 318:490-495

36. Murakami A, Ashida H, Terao J (2008) Multitargeted cancer prevention by quercetin. Cancer Lett 269:315-325

37. Cai Q, Rahn RO, Zhang R (1997) Dietary flavonoids, quercetin, luteolin and genistein, reduce oxidative DNA damage and lipid peroxidation and quench free radicals. Cancer Lett 119:99-107

38. Biscardi JS, Ishizawar RC, Silva CM, Parsons SJ (2000) Tyrosine kinase signalling in breast cancer: epidermal growth factor receptor and $\mathrm{c}-\mathrm{Src}$ interactions in breast cancer. Breast Cancer Res 2:203-210

39. Lee KW, Kang NJ, Heo YS, Rogozin EA, Pugliese A, Hwang MK, Bowden GT, Bode AM, Lee HJ, Dong Z (2008) Raf and MEK protein kinases are direct molecular targets for the chemopreventive effect of quercetin, a major flavonol in red wine. Cancer Res 68:946-955

40. Roberts PJ, Der CJ (2007) Targeting the Raf-MEK-ERK mitogen-activated protein kinase cascade for the treatment of cancer. Oncogene 26:3291-3310

41. Singhal RL, Yeh YA, Praja N, Olah E, Sledge GW, Weber G (1995) Quercetin down-regulates signal transduction in human breast carcinoma cells. Biochem Biophys Res Commun 208: 425-431

42. Lin CW, Hou WC, Shen SC, Juan SH, Ko CH, Wang LM, Chen YC (2008) Quercetin inhibition of tumor invasion via suppressing PKC delta/ERK/AP-1-dependent matrix metalloproteinase-9 activation in breast carcinoma cells. Carcinogenesis 29:18071815 